\title{
NUMERICAL MODELS OF STEADY-STATE THICKNESS AND BASAL ICE CONFIGURATIONS OF THE CENTRAL RONNE ICE SHELF, ANTARCTICA
}

\author{
by \\ M.A. Lange \\ (Alfred Wegener Institute for Polar and Marine Research, Postfach 120161 , \\ Columbusstraße, D-2850 Bremerhaven, Federal Republic of Germany) \\ and
}

D.R. MacAyeal

(University of Chicago, Department of the Geophysical Sciences, 5734 S. Ellis Avenue, Chicago, IL 60637, U.S.A.)

\section{ABSTRACT}

Radar ice-thickness surveys and bore-hole measurements suggest that the central part of Ronne Ice Shelf possesses a lobe-shaped basal layer of undetermined nature (probably saline ice). This layer is characterized by high radio-wave absorbtivity and by thicknesses up to approximately $300 \mathrm{~m}$. We reconstruct this basal layer and the associated ice-shelf thickness and flow distributions, using a time-dependent ice-shelf model forced with prescribed basal freezing rates. Characteristics of the basal layer are controlled by two factors: (i) long ice-column residence times in the unventilated pocket between Henry and Korff ice rises and Doake Ice Rumples, and (ii) basal freezing rates in this pocket that exceed the snow-accumulation rate (currently averaging $0.35 \mathrm{~m} / \mathrm{a}$ ice equivalent across the ice shelf).

\section{INTRODUCTION}

Radar surveys of the central part of Ronne Ice Shelf reveal a thick basal ice layer of undetermined nature that strongly absorbs radio waves and produces a strong internal reflection well above the true ice-shelf bottom (Crabtree and Doake 1986, Thyssen 1986). Diagnostic numerical models that include this region confirm independently that a thickness distribution in accordance with the basal layer yields better agreement between simulated and observed ice velocities (Lange and MacAyeal 1986). Measurements in an access bore hole (for its location, see Fig. 1) confirm the thickness and indicate that $63 \%$ of the local $465 \mathrm{~m}$ ice column lies below the internal radar-reflection horizon (Engelhardt and Determann 1987). Although it has not been confirmed conclusively, the basal layer is likely to be an accumulation of frazil sea-ice platelets like those which have been observed seaward of Filchner Ice Shelf (Dieckmann and others 1986). Given the low vertical heat flux through the ice shelf, such basal ice deposition is probably associated with circulation in the sub-ice-shelf cavity and with redistribution of basal ice in the manner of an oceanic ice pump (Lewis and Perkin 1986).

Basal sea-ice thickness gives a qualitative indication of the prevailing basal freezing process, but not a direct measure of the basal freezing rate as a function of space and time. This quantitative measure can be determined indirectly by accounting for the horizontal advection, strainrates and vertical heat flux that govern the basal sea-ice thickness as it co-evolves with the overall ice-shelf thickness and flow. In this study we reconstruct several distributions of basal sea ice in the central Ronne Ice Shelf for the prescribed basal freezing scenarios, using a

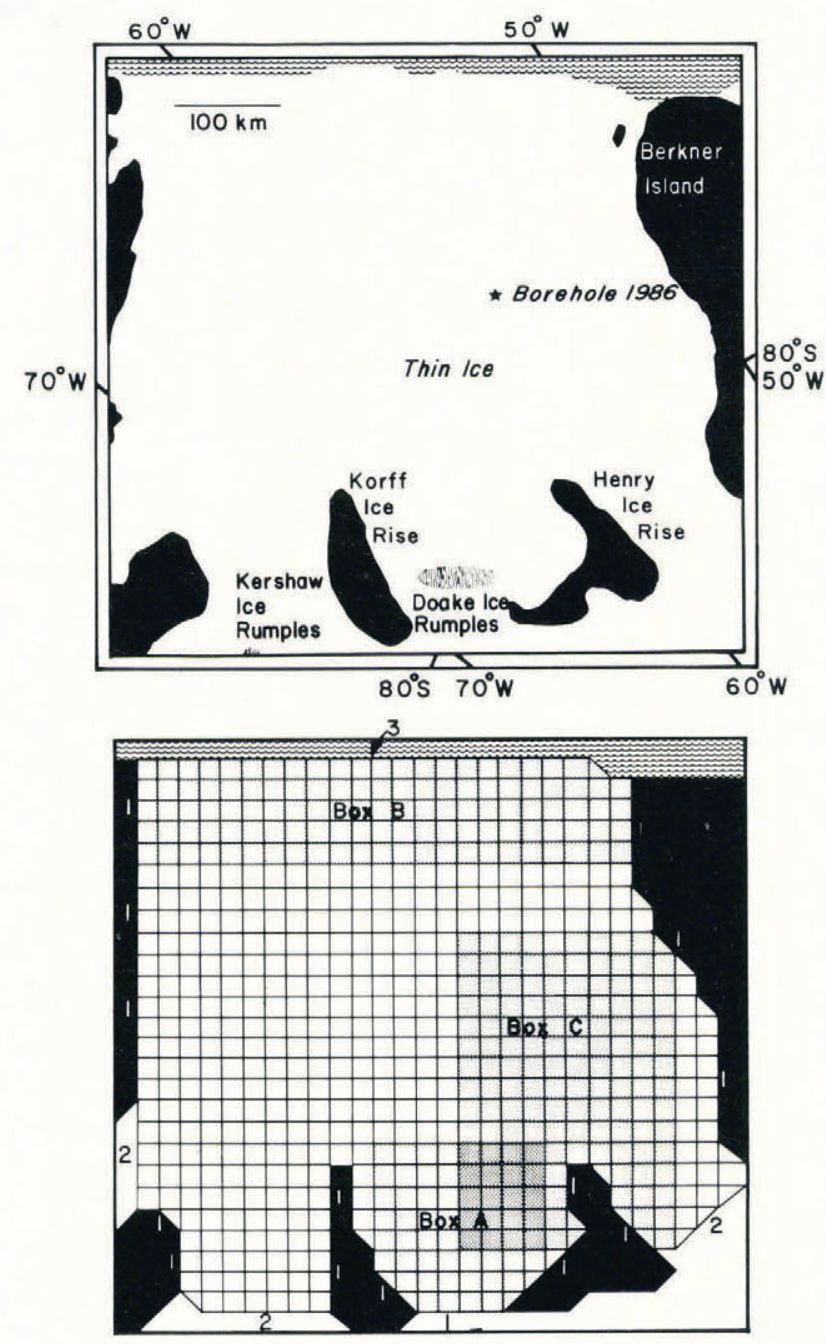

Fig. 1. The central part of Ronne Ice Shelf and its finite-element representation by our numerical model. Locations of ice streams that feed this part of the ice shelf are shown in McIntyre (1986). The annotation "thin ice" indicates those areas where radar surveys are unable to map the true ice-shelf thickness because of radar attenuation in a basal layer of undetermined nature (probably saline ice). Numbers along boundaries indicate boundary conditions referred to in Table I. 


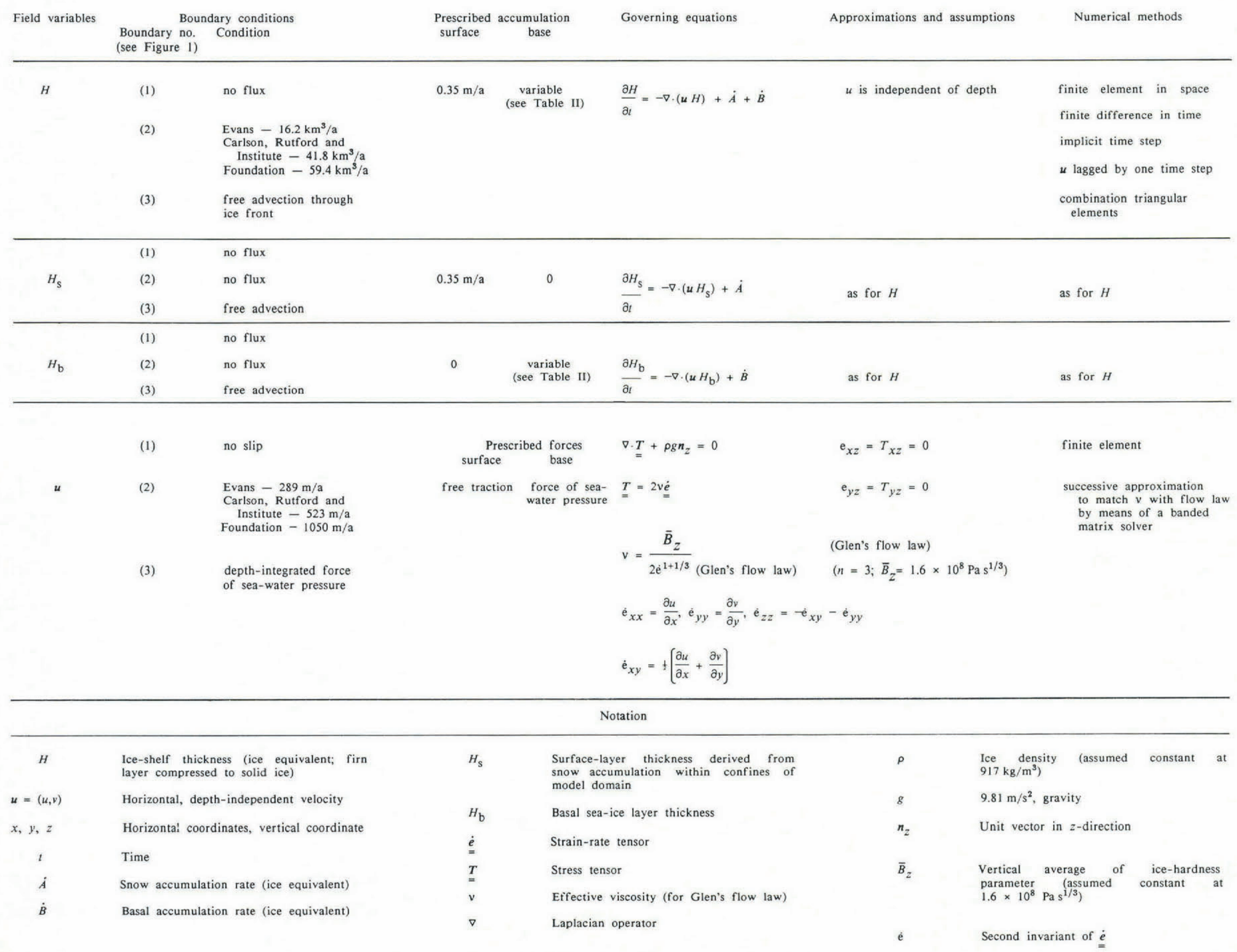


numerical ice-shelf model. We interpret these reconstructions in terms of how well they explain current observations and how they may constrain the sub-ice-shelf oceanic regime.

\section{METHODS}

We construct steady-state ice-shelf thickness, velocity and basal sea-ice distributions for a variety of prescribed basal freezing scenarios, using a time-dependent finiteelement model described by Lindstrom and MacAyeal (1986). As summarized in Table $I$, this model solves mass-continuity, stress-equilibrium and constitutive equations to determine the co-evolution of ice-shelf thickness $H$ and horizontal velocity $\boldsymbol{u}$ (assumed to be independent of depth in order to conform to lead-order ice-shelf dynamics) for prescribed ice-volume flux, velocity and stress-boundary conditions. We choose to disregard the thermal and compositional softening of the ice shelf associated with basal freezing in favor of a simple, uniform distribution of $\vec{B}$ (chosen to match values observed on Ross Ice Shelf; see Table 1) and will discuss these rheological effects in subsequent studies.

The numerical domain displayed in Figure 1 consists of the large central region of Ronne Ice Shelf where the basal ice layer has been observed (it has previously been regarded as an extended, central thin-ice zone). For computational efficiency, we exclude from this domain ice-shelf areas south of Henry and Korff ice rises. Snow accumulation and influx from the surrounding ice streams, and from ice-shelf areas up-stream of the numerical domain, are specified as indicated in Table I, using McIntyre's (1986) estimates of West Antarctic drainage patterns (for simplicity, we disregard spatial variation in the snow-accumulation rate). Discharge from Institute Ice Stream is assumed to enter west of Korff Ice Rise, and all discharge from Foundation Ice Stream is assumed to pass between Berkner Island and Henry Ice Rise. Specification of ice-stream widths, together with ice thicknesses, taken from the map of Crabtree and Doake (1986), allows balance inflow velocities of the ice streams to be estimated (Table I). For simplicity, Doake Ice Rumples (situated between Henry and Korff ice rises) are assumed to block completely ice flow from the south. Currently, ice velocities of up to $50 \mathrm{~m} / \mathrm{a}$ are observed across the rumples (Smith 1986). We prefer to treat the rumples as stagnant because of the technical limitations of our model in dealing with grounded ice.

Along with ice-shelf thickness $H$, the thicknesses of basal sea ice $H_{\mathrm{b}}$ and surface snow $H_{\mathrm{s}}$ (ice equivalent) are modeled, using two additional mass-continuity equations displayed in Table I. The model uses the total ice-shelf thickness $H$ to produce an associated flow field in its prognostic time-stepping scheme. The co-evolution of the surface and basal layers is thus simulated for a purely diagnostic purpose. The equations that govern $H_{\mathrm{b}}$ and $H_{\mathrm{s}}$ treat horizontal transport and vertical strain, but forcing and boundary conditions are altered to account for the generation of the separate ice categories only (the equation for $H_{\mathrm{b}}$ is forced, for example, by $\dot{B}$, but not by $\dot{A}$ ). No flux is specified at inland ice boundaries, except for the ice-stream inflows, and free advection (balance between ice velocity and iceberg calving) is specified at the seaward ice front. Basal sea ice originating up-stream of the southern boundaries of the modeled ice-shelf region, and delivered to the modeled region by transport through the boundaries, is not dealt with. In this approach, $H_{\mathrm{b}}$ and $H_{\mathrm{s}}$ represent accumulations within the confines of our numerical domain. The difference between $H$ and $\left(H_{\mathrm{s}}+H_{\mathrm{b}}\right)$ indicates the fraction of the ice column that was delivered to the ice shelf at the inland ice boundaries.

The internal radar-reflection horizon at $\left(H-H_{\mathrm{b}}\right)$, implied by our reconstructed basal ice distribution, can be verified by direct comparison with measurements (Crabtree and Doake 1986). This horizon further indicates the supposed transition between salty and pure ice, and the ice-column fraction which has salt-modified rheology (not accounted for here). Depending on the magnitude of $\mathrm{H}_{\mathrm{b}}$, the flow of the ice shelf will be considerably altered when taking into account the (as yet undetermined) different rheology of salty versus normal ice. The thickness of surface ice $H_{\mathrm{S}}$ indicates the burial depth of relict surface crevasses that may originate along the edges of the various ice rises and headlands. Steady-state trajectories of several imaginary relict crevasse bands, which allow ice-pocket residence times on the ice shelf to be estimated, are simulated here, following the technique of MacAyeal and others (1988, this volume).

To produce the steady-state distributions of $H, \boldsymbol{u}, H_{\mathrm{S}}$ and $H_{\mathrm{b}}$, the model is run for 6000 years, using a 20 year time step. Boundary conditions and accumulation rates are kept stable while the model equilibrates (after which all simulated fields are steady in time). Initial conditions required at model start-up are the total ice-shelf thickness and the thicknesses of the surface and basal layers (the stress-equilibrium equations that are solved for ice-shelf flow are not explicitly time-dependent, so do not require that initial conditions should be specified). The initial $H$ is specified as having a uniform seaward gradient (varying between $1000 \mathrm{~m}$ at the southern boundary and $200 \mathrm{~m}$ at the ice front), and the initial $H_{\mathrm{s}}$ and $H_{\mathrm{b}}$ are specified uniformly as zero. In all tests, manifestations of the arbitrary initial conditions are dissipated and steady state is reached within 4000 years. We verify the condition of steady state by monitoring discharge through the ice front in comparison with net accumulation and influx, and by monitoring time derivatives of the thickness distributions.

\section{EQUILIBRIUM CONFIGURATIONS}

We conducted numerous tests in which steady-state configurations of ice-shelf thickness, flow and basal sea-ice distribution were established from prescribed basal freezing scenarios. These configurations were examined and compared with data to provide: (i) general constraints on basal sea-ice distribution that were imposed by ice-shelf flow characteristics, (ii) the spatial relationship between basal sea-ice distribution and basal freezing patterns, and (iii) a crude estimate of the basal freezing conditions that produce the observed characteristics of Ronne Ice Shelf.

Basal freezing scenarios prescribed in three representative tests are described in Table II. Test 1 provides the

\section{TABLE II. BASAL FREEZING SCENARIOS}

$\begin{array}{lrl}\text { Test } & B(\mathrm{~m} / \mathrm{a}) & \text { Location }^{*} \\ & & \\ 1 & 0.1 & \text { everywhere } \\ 2 & 0.6 & \text { Box A } \\ & -0.2 & \text { Box B } \\ & 0.0 & \text { elsewhere } \\ & 0.6 & \text { Box C } \\ 3 & -0.2 & \text { Box B } \\ & 0.0 & \text { elsewhere }\end{array}$

* See Figure 1 for locations of boxes A, B and C.

reference configuration produced when basal freezing is spatially uniform. Tests 2 and 3 display the response to spatially variable basal freezing. Selection of the spatial patterns and magnitudes of basal freezing in tests 2 and 3 was arbitrary (as in the many other tests not reported here) because the glaciological and oceanographic data that would normally constrain such a selection are not available. The scenarios displayed here illustrate basic principles that apply to other scenarios tested, no matter how complex, and provide guidelines with which to interpret radar and bore-hole measurements.

Following intuition, ice-front radar surveys and massbalance estimates along apparent flow lines, we chose to apply strong basal freezing and melting rates in spatially limited areas designated in Figure 1 as boxes A-C. Spatially uniform basal freezing in excess of that specified in test 1 (Table II) was not considered feasible, given the low 
upward heat flux through the ice shelf. We thus selected smaller isolated basal freezing sites in accordance with the ice-pump mechanism, which could support freezing rates in excess of that supported by vertical heat flux alone. Freezing rates specified in boxes $\mathrm{A}$ and $\mathrm{C}$ thus conform to our intuitive expectation of strong, but spatially limited, ice-platelet deposition up-stream of the bore-hole site and the previously mapped thin-ice region (Fig. 1). The pocket between Henry and Korff ice rises and Doake Ice Rumples represented by box A (in test 2) was selected as one potential freezing site, on the basis of its strong regional basal slope (Smith 1986) and the mass-balance considerations reported by Doake (1987). Box C was selected (in test 3) on the basis of our experience in trying to match the observed basal ice thickness at the bore-hole site (sea ice emanating from box A passes west of the bore-hole site). Basal melting, treated in tests 2 and 3 , is prescribed in box B along the ice front, in order to be consistent with Kohnen's (1982) estimates of near-ice-front conditions, and to provide an approximate balance between net ice ablated and net ice accumulated (as expected in an oceanic ice-pump process which simply transfers ice from one location to another).

The $0.6 \mathrm{~m} / \mathrm{a}$ basal freezing-rate magnitude used in tests 2 and 3 was selected on the basis of its relationship to the

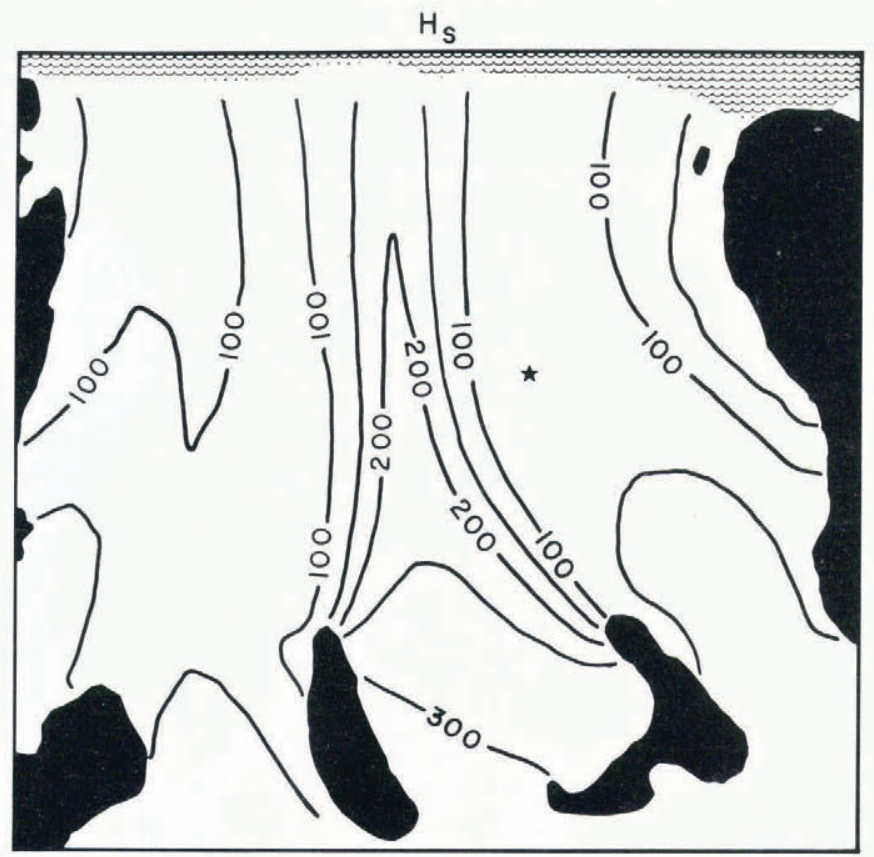

H

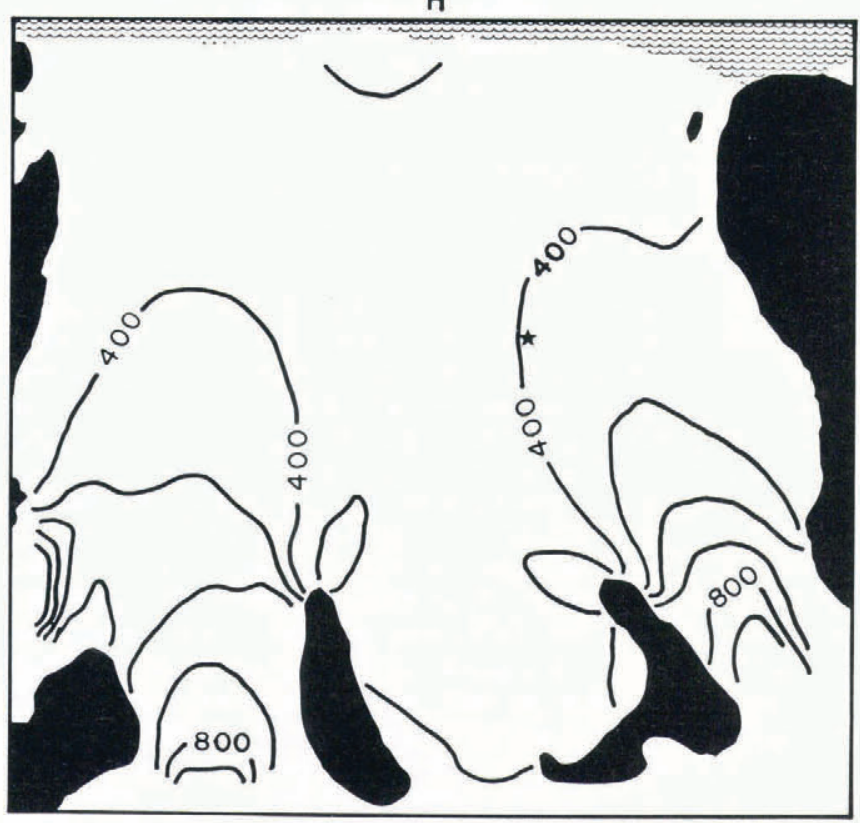

$0.35 \mathrm{~m} / \mathrm{a}$ (ice equivalent) snow-accumulation rate prescribed for the entire ice shelf (McIntyre 1986) and the 1.7 ratio of $H_{\mathrm{b}}$ to $\left(H-H_{\mathrm{b}}\right)$ observed at the bore-hole site (Engelhardt and Determann 1987). Ice columns originating in the pocket between Henry Ice Rise, Korff Ice Rise and Doake Ice Rumples contain little inland ice (as stated previously, we assume ice flux across the rumples to be zero), thus we assume

$$
H=H_{\mathrm{S}}+H_{\mathrm{b}}
$$

The ratio $H_{\mathrm{S}} / H_{\mathrm{b}}$ for a given ice column obeys an equation derived from the two separate mass-continuity equations for $H_{\mathrm{S}}$ and $H_{\mathrm{b}}$ (Table I):

$$
\frac{\partial}{\partial t}\left[\frac{H_{\mathrm{s}}}{H_{\mathrm{b}}}\right]=\frac{\dot{A}}{H_{\mathrm{b}}}\left[1-\frac{\dot{B} H_{\mathrm{s}}}{\dot{A} H_{\mathrm{b}}}\right)
$$

When $H_{\mathrm{S}} / H_{\mathrm{b}}$ is minimum or in steady state for a given ice column,

$$
\frac{\dot{B}}{\dot{A}}=\frac{H_{\mathrm{b}}}{H_{\mathrm{s}}}
$$
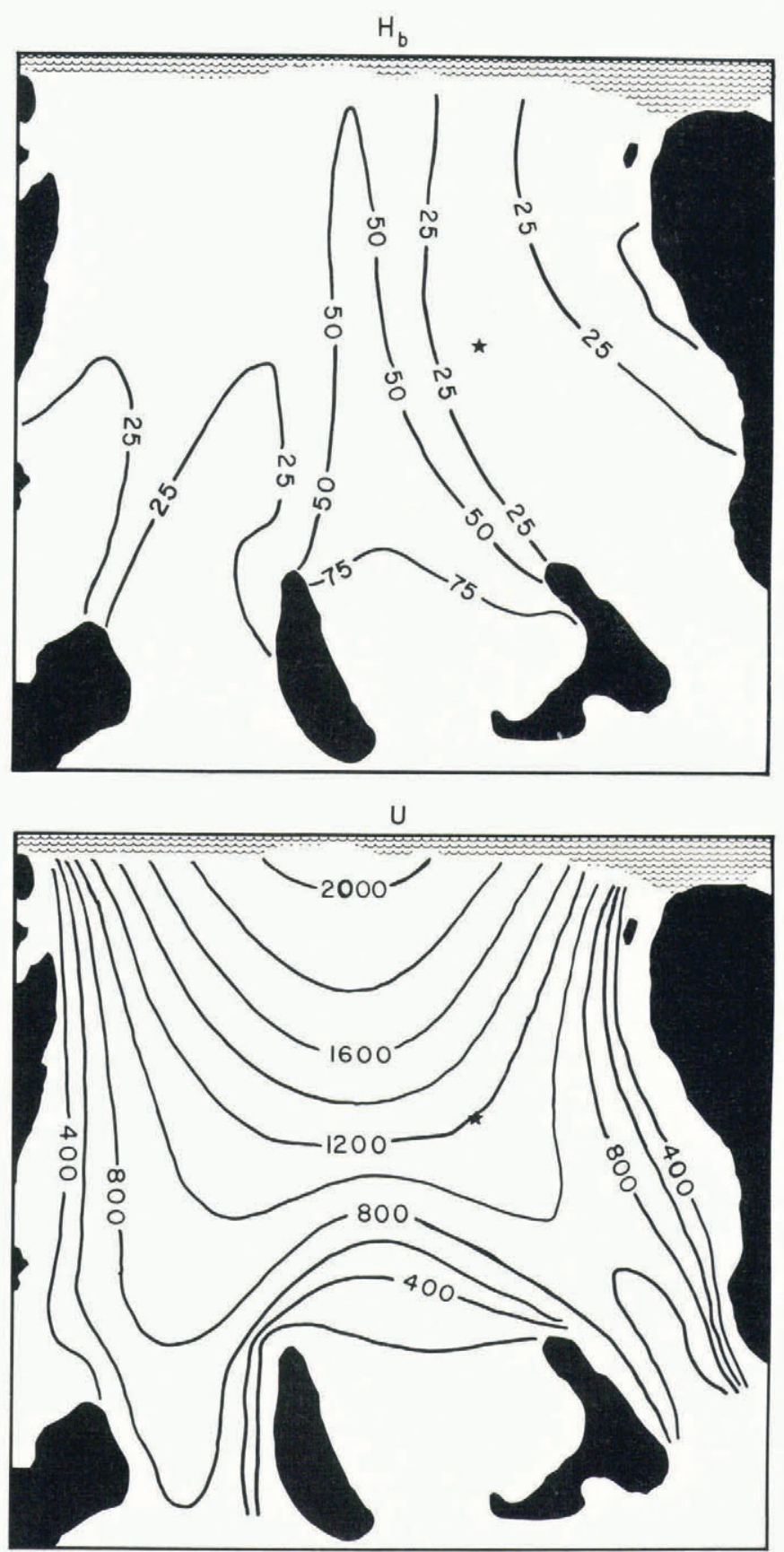

Fig. 2. The results of test $1 . H_{\mathrm{S}}, H_{\mathrm{b}}$ and $H$ contoured in meters, $U$ (velocity magnitude) contoured in meters per year. The star indicates the location of the bore hole. 
We do not know whether the ice column sampled at the bore-hole site possessed a minimum or a steady-state $H_{\mathrm{s}} / H_{\mathrm{b}}$ ratio, whether it originated within the pocket, or whether near-zero ice flux prevails across Doake Ice Rumples. Nevertheless, we can use the observed ratio of ice thickness above the internal-reflection horizon to thickness below the horizon as an arbitrary constraint on our selection of $\dot{B}$. Using Equation (3) (and the assumed value of $\dot{A}$ ), this observed ratio $(1 / 1.7)$ yields a basal freezing rate of $0.6 \mathrm{~m} / \mathrm{a}$. For want of better constraints, we adopted this value as a reference level with which to conduct tests 2 and 3. Basal freezing specified in test 1 was $0.1 \mathrm{~m} / \mathrm{a}$ and was selected to give an approximate equality in net sea ice accumulated among the three tests presented here.

The strongest constraint on basal sea-ice distribution, apart from the magnitude of basal freezing, was found to be the spatial variation in ice-column residence time within the ice shelf. This variation, in turn, is controlled by the distribution of ice rises and the locations and strength of ice-stream discharge. The results of test 1 , shown in Figure 2 , indicate that a wide basal sea-ice thickness range is obtained despite the uniform basal freezing rate prescribed. This range is produced by variation in the time required for given ice columns to traverse the ice shelf. Elapsed time since entering the ice shelf as a function of distance along selected particle trajectories is shown in Figure 3. Those

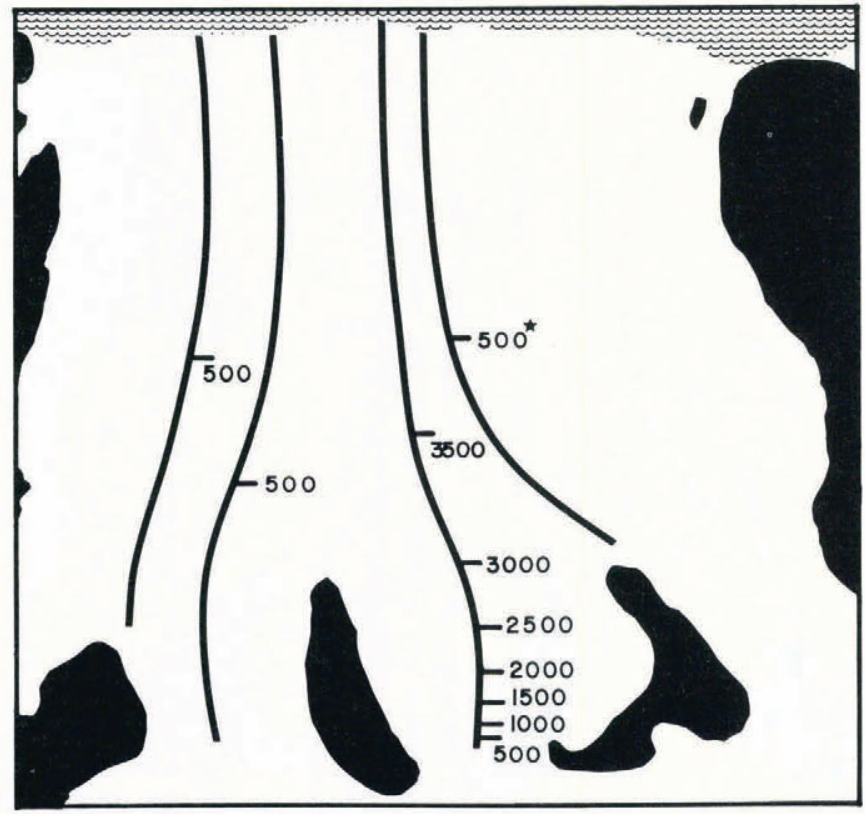

Fig. 3. Steady-state particle trajectories with elapsed residence time within the ice shelf, indicated in years. Results from test 1 .

columns resident longest within the ice shelf have the greatest accumulations of surface and basal ice. A basal sea-ice layer is evident in the side parts of the ice shelf which are flushed by strong ice-stream discharge, but its thickness is reduced by the relatively short time that ice columns spend within these regions of the ice shelf.

Also shown in Figure 2 are the distributions of $\mathrm{H}, \mathrm{H}_{\mathrm{S}}$ and the velocity magnitude $U$. Total thickness $H$ can be compared with the maps of apparent thickness which have been produced by Crabtree and Doake (1986). Agreement is generally good except where the simulation fails to produce a significant thinning (by several hundred meters) within the apparent thin-ice zone of suspected basal sea ice (Fig. 1). Simulated velocity magnitude is in approximate agreement with the available observations (Lange and Kohnen 1985, Kock and Wiegand 1986), but is approximately $20 \%$ too high at the ice front. This error can be attributed to the many simplifications of our model, such as the uniform ice-stiffness parameter, and can be corrected in subsequent studies. The distribution of $H_{\mathrm{S}}$ shows the same pattern as $H_{\mathrm{b}}$, indicating that ice-shelf residence time basically controls the thickness of any internal layer. The values of $H_{\mathrm{s}}$ correspond to those of $H_{\mathrm{b}}$ in the ratio expected from Equation (3), despite the fact that Equation (3) assumes a Lagrangian frame of reference.
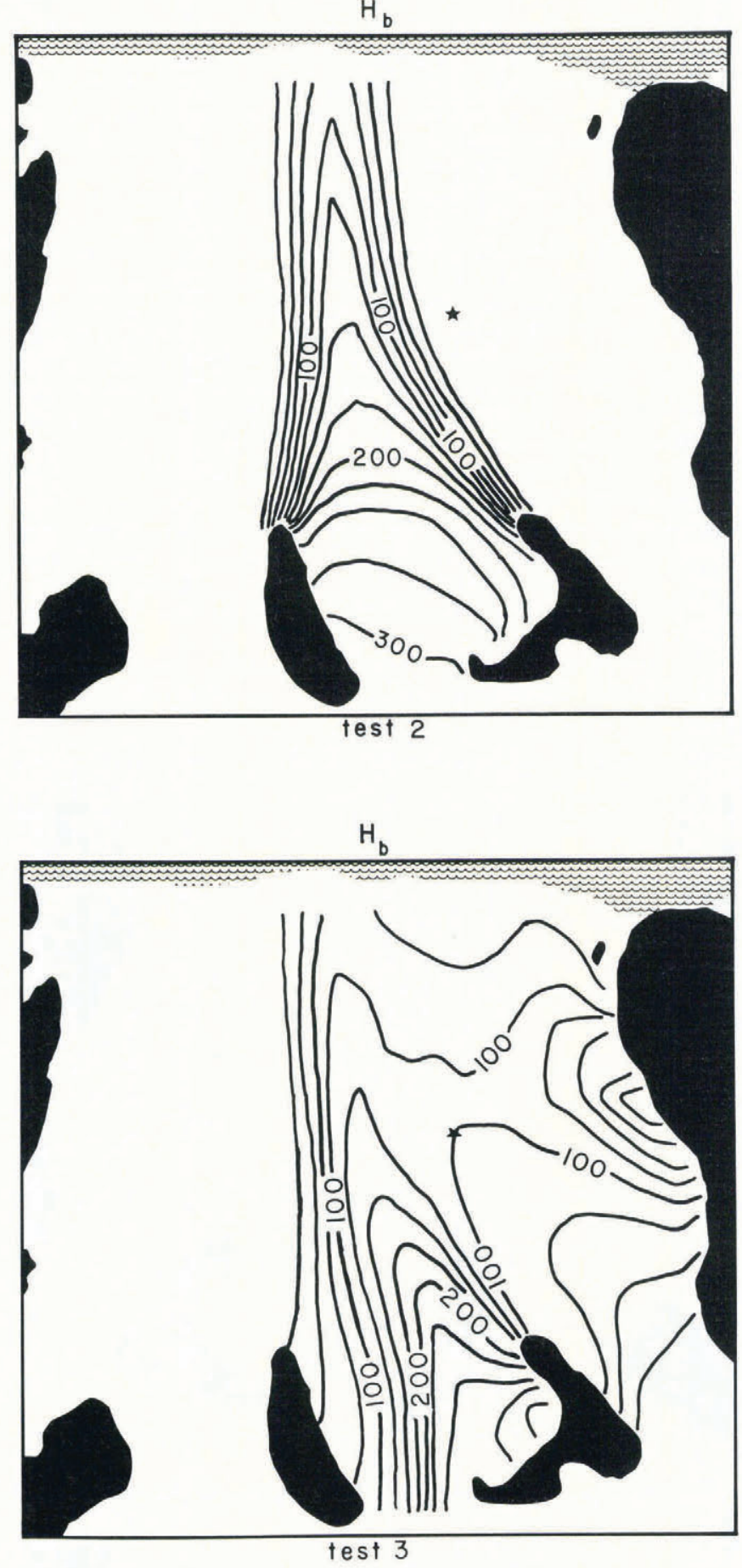

Fig. 4. $H_{\mathrm{b}}$ in meters in tests 2 and 3.

Tests 2 and 3, in which strong regional basal freezing is specified in boxes $\mathrm{A}$ and $\mathrm{C}$ respectively, produce thick basal sea-ice lobes that are consistent with the observed profile of the internal radar-reflection horizon. The distribution of $H_{\mathrm{b}}$ and $\left(H-H_{\mathrm{b}}\right)$ in these tests is displayed in Figures 4 and 5 respectively. The maps of $\left(H-H_{\mathrm{b}}\right)$ can be compared directly with the radar-derived map of apparent ice-shelf thickness (Crabtree and Doake 1986), in which the top of the basal ice layer is misinterpreted as the true ice-shelf bottom. Agreement between the apparent thin-ice zone of the radar map and simulated distribution of $\left(H-H_{\mathrm{b}}\right)$ is, in qualitative terms, quite good. Other thin-ice zones, such as that extending seaward of Fowler Peninsula, reported by Crabtree and Doake (1986), are not reproduced because basal freezing was not specified in these areas. The coarse $(20 \mathrm{~km})$ spatial resolution of our numerical model also contributes to the dissipation of small-scale structure apparent in the radar maps of other thin-ice areas. 


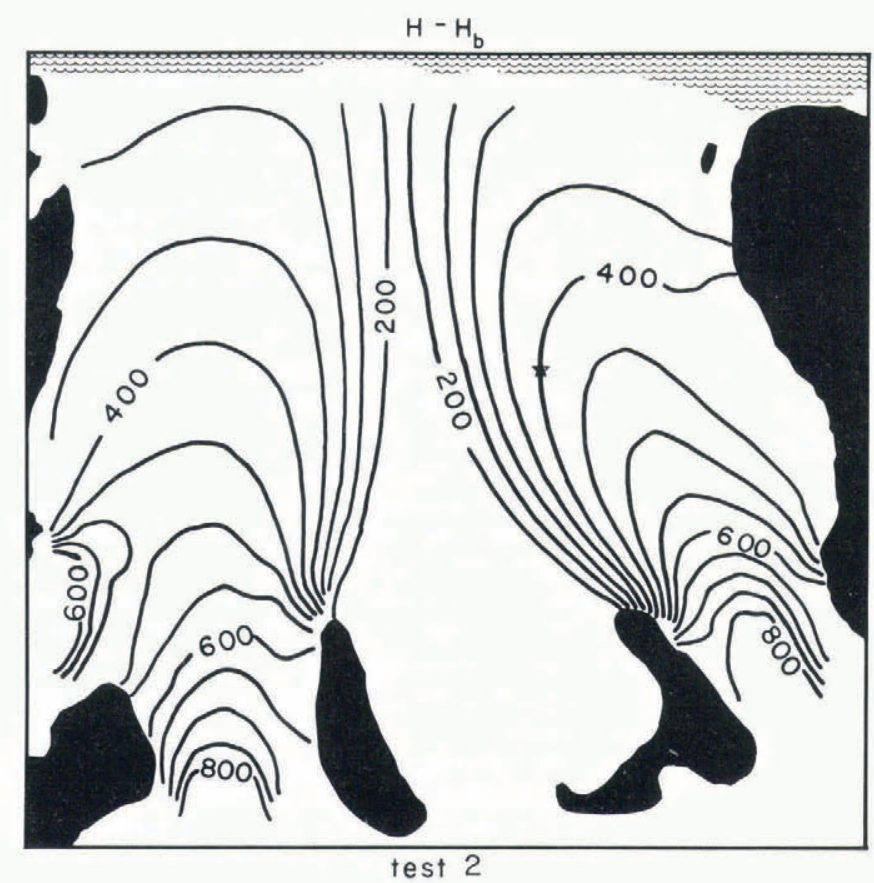

Improved agreement between simulated basal ice configuration and available data was achieved in the above-mentioned additional tests by: (i) varying the location and magnitude of basal freezing, (ii) reducing discharge from Foundation Ice Stream to below $25 \%$ of that proposed by McIntyre (1986), and (iii) calculating ice-shelf thickness, flow and basal sea-ice configurations that are unsteady in time. Points (i) and (ii) indicate the sensitivity of our reconstructions to boundary conditions and oceanographic forcing. Improvements in the specification of these elements in future numerical simulations can be achieved by direct field observations of ice-stream discharge rates and sub-ice-shelf circulation.

The possibility that the observed characteristics of the basal layer are not in steady state, with long-term basal freezing patterns, is motivated by current evidence from other ice shelves for ice-shelf transience. Thickness patterns on Ross Ice Shelf in the vicinity of Crary Ice Rise, for example, are known to deviate significantly from steady state as a result of current ice-stream discharge fluctuations (MacAyeal and others 1987). If we adopt the hypothesis of transient ice-shelf behavior, a possible scenario, leading to the thick basal deposits at the bore-hole site, could involve the sudden flushing of the isolated pocket between Henry and Korff ice rises. Such flushing might be triggered by sudden breakdown of Doake Ice Rumples. The results from our model (not shown here) indicate that the thick basal ice deposit is possibly maintained in this pocket when the ice rumples block influx from the south (as demonstrated by test 2) and the deposit could be transported rapidly to the bore-hole site without significant thinning. If such a scenario is responsible for the high basal ice thickness currently observed at the bore-hole site, then tests we have conducted suggest that flushing of the pocket must have occurred between 200 and 500 years ago.

\section{CONCLUSION}

Our numerical reconstructions show that the observed lobe-shaped basal sea-ice deposit in the central Ronne Ice Shelf is a natural consequence of long ice-column residence times within the central part of Ronne Ice Shelf. Unlike the areas to the east and west, which are efficiently flushed by ice-stream discharge, long residence time within the unventilated pocket between Henry and Korff ice rises promotes build-up of substantial basal sea ice even if the basal freezing rate is low. The ratio of basal sea-ice thickness to surface-ice thickness in a given ice column is determined, under these circumstances, by the ratio of $B$ to $A$ within the region in which the given ice column resides for a substantial period. For the present snow-accumulation rate of $0.35 \mathrm{~m} / \mathrm{a}$ (ice equivalent), basal freezing at $0.60 \mathrm{~m} / \mathrm{a}$ (ice equivalent) within the pocket can produce basal ice thicknesses in the range inferred from radar surveys and bore-hole measurements.

Several important extensions to our experiments remain to be carried out in future work. First, better knowledge of ice-shelf boundary conditions, provided by field surveys of ice-stream outlets and ice rumples, is required. Secondly, thermal and compositional controls on ice rheology must be modeled, along with ice-shelf thickness and flow. Success in this task will require analysis of ice cores from the central Ronne Ice Shelf, as well as accurate definition of the flow law applicable to saline ice. Finally, the sub-ice-shelf oceanography needs to be more clearly understood, in order to improve our ad hoc representations of basal freezing.

\section{ACKNOWLEDGEMENTS}

This research was supported by U.S. National Science Foundation grant DPP 85-09451 and a NATO geosciences program grant. We thank Dean Lindstrom for drafting the figures, Glenda York for typing the manuscript, and Drs Engelhardt, Doake and Thyssen for productive discussions. We also thank an anonymous reviewer for helpful comments. This is contribution No. 71 of the Alfred Wegener Institute for Polar and Marine Research. 


\section{REFERENCES}

Crabtree, R.D., and C.S.M. Doake. 1986. Radio-echo investigations of Ronne Ice Shelf. Ann. Glaciol., 8, $37-41$.

Dieckmann, G., G. Rohardt, H. Hellmer, and J. Kipfstuhl. 1986. The occurrence of ice platelets at $250 \mathrm{~m}$ depth near the Filchner Ice Shelf and its significance for sea ice biology. Deep-Sea Res., 33(2), 141-148.

Doake, C.S.M. 1976. Thermodynamics of the interaction between ice shelves and the sea. Polar Rec., 18(112), 37-41.

Doake, C.S.M. 1987. Some aspects of the flow of the Ronne Ice Shelf. In Veen, C.J. van der, and J. Oerlemans, eds. Dynamics of the West Antarctic Ice Sheet. Proceedings of a Workshop held in Utrecht, May 6-8, 1985. Dordrecht, etc., D. Reidel Publishing Company, 75-98.

Engelhardt, H., and J. Determann. 1987. Borehole evidence for a thick layer of basal ice in the central Ronne Ice Shelf. Nature, 327(6120), 318-319.

Kock, H., and A. Wiegand. 1986. Glaciological geodesy on Filchner Ice Shelf 1983-86. In Kohnen, H., comp. Filchner-Ronne-Ice-Shelf-Programme. Report No. 3. Bremerhaven, Alfred-Wegener-Institute for Polar and Marine Research, 37-42.

Kohnen, H. 1982. Glaciological investigations in the frontal zone of the Filchner and Ronne ice shelves. Ann. Glaciol., 3, 160-165.

Lange, M.A., and H. Kohnen. 1985. Ice front fluctuations in the eastern and southern Weddell Sea. Ann. Glaciol., 6, 187-191.

Lange, M.A., and D.R. MacAyeal. 1986. Numerical models of the Filchner-Ronne Ice Shelf: an assessment of reinterpreted ice thickness distributions. J. Geophys. Res., 91(B10), 10457-10462.

Lewis, E.L., and R.G. Perkin. 1986. Ice pumps and their rates. J. Geophys. Res., 91(C10), 11756-11762.

Lindstrom, D.R., and D.R. MacAyeal. 1986. Paleoclimatic constraints on the maintenance of possible ice-shelf cover in the Norwegian and Greenland seas. Paleoceanography, 1(3), 313-337.

MacAyeal, D.R., R.A. Bindschadler, K.C. Jezek, and S. Shabtaie. 1988. Can relict crevasse plumes on Antarctic ice shelves reveal a history of ice-stream fluctuation? Ann. Glaciol., 11, 77-82.

MacAyeal, D.R., $\quad$ R.A. Bindschadler, S. Shabtaie, S. Stephenson, and C.R. Bentley. 1987. Force, mass, and energy budgets of the Crary Ice Rise complex, Antarctica. J. Glaciol., 33(114), 218-230.

McIntyre, N. 1986. Discharge of ice into the Filchner-Ronne ice shelves. In Kohnen, H., comp. Filchner-Ronne-Ice-Shelf-Programme. Report No. 3. Bremerhaven, Alfred-Wegener-Institute for Polar and Marine Research, 47-52.

Smith, A.M. 1986. Ice rumples between Korff and Henry ice rises. In Kohnen, H., comp. FilchnerRonne-Ice-Shelf-Programme. Report No. 3. Bremerhaven, Alfred-Wegener-Institute for Polar and Marine Research, 85-90.

Thyssen, F. 1986. The central part of the Filchner/Ronne Ice Shelf. In Kohnen, H., comp. FilchnerRonne-Ice-Shelf-Programme. Report No. 3. Bremerhaven, Alfred-Wegener-Institute for Polar and Marine Research, 81-83. 